\title{
POTENCIALIDADES HUMANAS Y CAPACIDADES TERRITORIALES: SENDAS PARA EL POSTCONFLICTO EN COLOMBIA
}

\section{Potentiels humain et la CAPACITÉ TeRritoriale: CHeMins POUR POST-CONFlit EN Colombie}

\author{
Luis Felipe Bastidas Aguilar \\ Universidad de Nariño
}

\section{Resumen}

El presente artículo asume el postconflicto como una construcción social que en Colombia, como proceso en marcha, supone una dinámica que requiere de unos elementos estratégicos alternos para el balance entre las transformaciones socioculturales e institucionales que se configuran durante la profundización y el fortalecimiento de la Paz. Se busca armonizar el tema de postconflictoabordando dos sendas estratégicas en las políticas institucionales surgidas desde el modelo top-down, pero que proyectadas bajo los principios de endogénesis, contextualidad y de trópico, representan una alternativa para el retorno de la Colombia de la "raza cósmica". Para ello se realiza una revisión bibliográfica generando, desde el concepto de Construcción de Paz, el relevante apalancamiento de las potencialidades humanas a través de la Reconciliación Social y, en torno al concepto de Diseño institucional, el fortalecimiento de las capacidadespolíticas territoriales de las entidades sub-nacionales "excluidas". Sendas y principios que representan legitimidad, estabilidad política, promoción de prácticas deliberativas, ciudadanías empoderadas, gobernabilidad y Paz.

Palabras clave: construcción de paz, descentralización, entidades subnacionales excluidas, Postconflicto, Reconciliación social.

\section{Résuimé}

Cetarticlesuppose la post-conflitcomme une constructionsocialequi en Colombie, comme processus continuest une dynamique qui nécessite certain séléments stratégiques de rechangevisant l'équilibre entre les transformations socio-culturelles et institutionnelles qui sont configurés pour l'approfondissement et le renforcement de la paix.Il vise à harmoniser la question de la post-face deux voi esstratégiques dans les politiques institution nelles émergents du modèle top-down, mais qui a projeté dans le cadre des principes de endogenèse, la contextualité et tropiques, ils représentent une alternative aure tour de la Colombie de «racecosmique». Pour faire une revue de la littérature se fait générer, à partir du concept de consolidation de la paix, l'effet de levier potentiel humain concerné par la réconciliation sociale et autour du concept de la conception institutionnelle, renforcement des capacités des entités politiques régionales sous-national «exclus». Les chemins et les príncipes qui représentent la légitimité, la stabilitépolitique, la promotion de pratiques délibératives, habilité la citoyenneté, de la gouvernance et de la paix.

Mots-clés: consolidation de la paix, décentralisation, les entités infra nationales exclus, post-conflit, la réconciliation sociale.

Recibido: 31 de julio de 2015

Aceptado: 10 de noviembre de 2015

1 Docente Licenciatura en Etnoeducación. UNAD CEAD Pasto, Colombia. Sociólogo de la Universidad de Nariño, Especialista en Gobierno, gerencia y asuntos públicos, Magister (c) en Gobierno y Políticas Públicas de la Universidad Externado de Colombia. Contacto: Luis.Bastidas@unad.edu.co. 
La generación de la violencia a la que tuve el infortunio y también el privilegio del reto de pertenecer está a punto de desaparecer. Con todo respeto asumo su vocería para declarar que no queremos dejar nuestro legado tal como queda, tan incompleto, a la siguiente generación de colombianos. El proceso de cambios (...) requiere una reconstrucción y un renacer plenos: el 'kasiyadu' y sobre todo una más clara decisión y empuje para desalojar del poder a los responsables de la violencia, a los reanimadores de la guerra, a los genuflexos adoradores de los imperios que nos atrofian.

La Violencia en Colombia (Fals Borda, 2005, p. 23).

\section{Introducción}

A nivel global, los procesos de postconflicto, han promovido el surgimiento de iniciativas y actitudes propositivas de diferentes sectores de la sociedad, que se manifiestan para entablar una nueva realidad a construir y que invitan nuevamente a pensar en la utopía. Este artículo, particularmente, hace énfasis en los caminos de construcción de paz desde los procesos de Reconciliación Social, y los caminos del Diseño institucional como nueva forma de poder político desde la descentralización basada en las entidades subnacionales "excluidas", para el fortalecimiento de las potencialidades humanas y de las capacidades territoriales, respectivamente.

En Colombia, una situación extrema de guerra por más de 40 años, ha generado una mayor creatividad y un mayor arrojo por parte de los actores sociales, tanto públicos como privados, originando acciones y comportamientos de solidaridad y de necesidad de Paz, incluso se han logrado conquistar algunos espacios institucionales como decretos, agendas, programas, fundaciones, etc., donde ya se visibilizan escenarios que proyectan nuevas dinámicas sociales, políticas y económicas afines a la paz.

Desde la opinión pública, se tiene mayor claridad en que la firma de acuerdos con los grupos armados no significaría el fin de la violencia pero sí podría enfocar al país hacia un cambio de mentalidad, de imaginarios, de sistema de creencias, para reducirla, aprender a superarla y alcanzar nuevas oportunidades que ampliarán el agendamiento público también a nuevas posibilidades, pendientes por décadas.

En el marco de los acuerdos de Paz en La Habana, el tema del postconflicto se visibiliza cada vez con mayor fuerza. El artículo aborda el tema como proceso de construcción social y se exponen algunos avances conceptuales que permiten identificar los componentes y retos que lo rodean. Este análisis ha dirigido la atención en dos escenarios a partir de los cuales se ha propuesto observaciones también desde la revisión teórica de contextos viables. Para ello, en dicho análisis influyen tres puntos clave: lo endógeno, lo contextual y el concepto de "trópico" (Fals Borda, 2003, p. 3-6).

El proceso de postconflicto, abre el telón para una nueva escena que se espera guíe y sostenga un estado de transición social, política, cultural y económica; posterior al análisis del concepto se identifican, de acuerdo a la revisión de la literatura,los principales componentes o "retos" del postconflicto (en su dimensión política), que posibilitarían la escenografía hacia ese estado de transición, a saber: "la reforma al diseño institucional, la reintegración política de excombatientes, la reconciliación politica, y la profundización de la democracia" (Ugarriza, 2013, p 146).

Para fines de éste artículo, y de acuerdo a los principios enunciados, se profundizará el análisis en torno a dos componentes o retos en particular. En primer lugar, se tratará un análisis frente al componente de la Reconciliación como parte del concepto de "Construcción de Paz" o Peacebuilding. En este sentido, el término reconciliación se piensa desde una acción simétrica y en espiral, que se erige de la acción a la reflexión y de la reflexión a la acción, acción que en términos del sociólogo Orlando Fals Borda, se traduce en una acción "sentipensante".

En cuanto al Diseño institucional, éste relacionado a la territorialidad y a la preocupación que desde los años 90's aún figura como una posibilidad pendiente en la agenda nacional, se presenta una reflexión 
que debe asumir el postconflicto como proceso de construcción local en cuanto a priorizar las realidades geosocioculturales sobre la actual organización política-administrativa que desconoce las identidades poblacionales, y que figura como uno de los motores del conflicto histórico: población-territorio. Se trata el tema desde la descentralización como aporte al fortalecimiento de las capacidades políticas de las denominadas: entidades subnacionales "excluidas" y en las cuales también habitan grupos sociales excluidos históricamente, entre ellos y para el caso de este documento, se hace referencia principalmente a los grupos étnicos, que figuran además, como la población que ha sufrido mayor victimización del conflicto armado en Colombia.

El posconflicto

Pertenezco a la generación de la violencia. Soy uno de los muchos universitarios que en 1949 veía con estupor esa violencia que tenía algo de falsa, no justificable, insuficiente para producir ese horror y esa catástrofe. Esa violencia sin propósitos, sin agudeza, fue haciendo de nosotros hombres y mujeres preparados inconscientemente para la

De acuerdo con la literatura y el naciente bagaje teórico que se empieza a dimensionar alrededor del postconflicto, se entiende éste como un período de tiempo en el cual se superan los conflictos armados, sea parcial o totalmente. El fin de un conflicto armado, puede presentarse por la vía negociada o por vía victoria/derrota armada, según la tendencia global "después de 1989, la proporción de conflictos armados que finalizaron en una mesa de negociación se duplicó -de 9\% entre 1946 y 1989, a 18\% entre 1990 y $2005-$, mientras que la de victorias militares de alguna de las partes se redujo de forma drástica -de 54 a 14\% en el mismo período"(Ugarriza, J., 2003, p, 144).

Uno de los parámetros que evidencian escenarios de postconflicto es la disminución de homicidios por el conflicto armado. Comprender la importancia del fin del conflicto armado bajo una tendencia de negociación, permite evidenciar con mayor relevancia, esos parámetros cuantitativos.

Colombia, el proceso de negociación entre el Gobierno del presidente Santosy la guerrilla de las FARCEP, posibilitan proyectar un periodo constructivo de postconflicto. Teniendo en cuenta el balance de los datos en cuanto a reducción de homicidios por el conflicto armado en Colombia, bajo la perspectiva anunciada, existe ya una reducción de dicho flagelo, como lo afirma (Justicia y Nación, 2015):

La tasa nacional de homicidios (el número de casos por cada 100.000 habitantes) podría estar por debajo de 30, lo que no se logra desde finales de los 70. (...) la cifra de miembros de la Fuerza Pública muertos en servicio en el 2014 llegó a 260. Este número es inferior al del 2013, cuando alcanzó los 343. Se convierte en la cifra más baja en diez años, según el Ministerio de Defensa Nacional. La cifra más alta fue la del 2005, con 629 uniformados. (...) De otro lado, el número de guerrilleros muertos en combate fue de 275 en el 2014. Se convierte en una cifra inferior a la del 2013, año en que se reportó un total de 316 subversivos dados de baja.

Según Jorge Restrepo, director del Centro de Recursos para el Análisis de Conflictos (Cerac), señala que "hay muchas regiones que ya no tienen presencia de grupos asociados al conflicto armado y eso se traduce en una reducción de la violencia homicida". (Justicia y Nación, 2015).

Igualmente en el tema de hechos victimizantes, la reducción de sucesos es considerable, según lo afirma el artículo de la página virtual de El tiempo (Política, 2014) teniendo en cuenta el informe sobre el conflicto armado que presentara en agosto del 2014, la oficina OCHA de la ONU en Colombia: 
El informe (...) muestra que la decisión de negociar en medio de la guerra tiene costos humanos, pero que los diálogos están permitiendo reducir la intensidad del conflicto. (...) Al comparar la cifra de 305.624 desplazados que registró Naciones Unidas en los dos últimos años (mientras se dialoga en Cuba) con las 744.777 víctimas del mismo fenómeno ilegal que, según la Red Nacional de Información de la Unidad de Víctimas se presentaron entre 2010 y 2012, hay una reducción de 439.153 afectados por este delito.

En concordancia con los sucesos, es interesante el concepto de Galtunf, para quien los conflictos entendidos de forma positiva, pretenden un escenario constructivo en cuanto a generadores de transformación social, a su vez, por la implicación pedagógica que requieren, ya que posibilita el espacio para enseñar/aprender a gestionar los conflictos. El autor propone el reconocimiento del"triángulo de la violencia” para interpretar su dinámica, desde la violencia directa, la violencia estructural que evidencia la existencia de estructuras injustas que no permiten la satisfacción de las necesidades y requiere planes y programas para transformar la sociedad y crear el bienestar colectivo. Y la violencia cultural generadora de legitimación de esas conductas a través de actitudes, estereotipos y visiones. (Arteaga, 2006)

De acuerdo a la revisión bibliográfica en torno al postconflicto es preciso detallar los componentes o retos, que bajo la perspectiva de Angelika Rettberg (2002), se reconocen también como "temas estratégicos":

Resumen de temas estratégicos para la preparación del post-conflicto en Colombia:

1) Apoyo a recuperación post-conflicto: Atención humanitaria a víctimas del conflicto. Retorno y apoyo de poblaciones desplazadas. Desmovilización/reintegración de excombatientes. Desminado. 2) Reconstrucción de infraestructura Temas económicos: Restauración de capacidad de manejo económico. Generación de recursos para el post-conflicto. Narcotráfico. Papel del sector privado. 3) Temas políticos y de administración del Estado: Adecuación y fortalecimiento de instituciones estatales. Ordenamiento territorial. Instituciones políticas para compartir el poder 4) Temas judiciales: Restauración o consolidación del Estado de derecho. Justicia transicional. 5) Comisiones de la verdad Temas sociales: Procesos sociales de perdón y reconciliación. Grupos sociales vulnerables. Fomento al resurgimiento y consolidación de la sociedad civil. 6) Temas militares: Estrategia de seguridad para el post-conflicto. Organización de las Fuerzas Armadas y de la Policía. Gasto militar y post-conflicto. 7) Temas internacionales: Recursos para apoyar la construcción de paz y el post-conflicto. Facilitación, mediación y verificación. Derecho Internacional Humanitario. (p. 19).

De acuerdo a lo anterior, los componentes, retos, temas estratégicos o caminos del postconflicto deben contener un alcance socio-político y territorial. Según Ugarriza (2013), la estabilidad política que se aborda en un proceso de postconflicto debe posibilitar que los ciudadanos legitimen los mecanismos legales para priorizar, implementar, evaluar alternativas de solución sobre el agendamiento público, así mismo señala que:

Entre 1989 y 2012, las agendas políticas de los procesos de paz en el mundo incluyeron la discusión sobre elecciones, creación de gobiernos interinos, integración de rebeldes a las Fuerzas Armadas, conversión de grupos armados en organizaciones políticas, acuerdos de poder compartido nacionales o locales, autonomías, derechos culturales, desarrollo regional, referendos sobre temas sensibles (e.g., estatus de un territorio), federalismo, independencia y redacción de una nueva constitución.(p.147)

A continuación, teniendo en cuenta los caminos del postconflicto enunciados anteriormente, se realiza en detalle, el análisis de dos campos identificados como esenciales y de relevancia tanto desde el enfoque normativo, institucional y sociocultural, denominados como sendas del postconflicto.

\section{La construcción de paz. (Peacebuilding "top-down”)}

El concepto de Construcción de Paz incluye uno de los puntos clave o senda del postconflicto, pero antes, es preciso identificarlo también como proceso institucional, que desde el método "top down", conserva algunas pautas interesantes al debate. Como lo afirman Charbonneau, B y Parent, G. (2012) 
existe una amplia discusión acerca de los enfoques "top-down" y "bottom-up" que se orientan en diferente dirección frente a la preocupación por implementar el proceso de construcción de paz o "Peacebuilding", pero se ignora que ambos enfoques pueden aportar significativamente al proceso, y es lo que se pretende exponer antes de abordar las sendas del postconflicto:

Institutional reforms and better state and international policies are obviously badly needed, but trauma cannot be addressed and healing cannot progress without proper social conditions, just as peace and reconciliation cannot be supported and advanced without engaged and healthy citizens. (p. 12)

Es preciso aclarar que el modelo Top-down asume la implementación, de las decisiones del Gobierno o políticas públicas, desde la administración pública,en la cual ésta se reconoce como el principal actor y quien ejecuta las decisiones públicas, del centro a la periferia, no permite delimitar cambios en la política o procesos de aprendizaje, utilizada en los países en vía de desarrollo "donde no hay canales suficientes de participación y la sociedad civil está poco organizada" (Ordońez-Matamoros, 2013); por su parte, el modelo Botton-up, no valida la jerarquización ni centralización de las decisiones, la ciudadanía junto a la administración pública actúan coordinadamente desde la situación problemática, promociona la participación ciudadana desde la construcción de consensos, pero, según Ordońez, predomina en países desarrollados donde la "sociedad civil aporta organizadamente" (p. 216).

Sin embargo, constituida la estabilidad política a través del postconflicto y desarrolladas progresivamente las sendas del postconflicto: Reconciliación social y nuevo Diseño institucional, pueden permitirse y construirse escenarios donde tanto las reformas institucionales, decisiones desde el Estado, serían tan vitales y congruentes con las opciones que se abordan desde lo local o desde la ciudadanía, desde las poblaciones que habitan las entidades subnacionales "excluidas", incluso desde la mismas víctimas, asumiendo una actitud endógena y no paternalista.

Entre tanto, los procesos de Construcción de Paz dependen de la consolidación del posconflicto, así sea en algunos territorios, regiones o municipios.La construcción de paz según Angelika Rettberg (2012) es un proceso en el que las acciones y escenarios, principalmente institucionales e institucionalizadas, buscan evitar la recaída en el conflicto armado propiciando el reconocimiento de las causas del conflicto y atendiendo o superando las consecuencias del mismo. Los principales escenarios de construcción de paz en Colombia se fortalecen a raíz de la formulación e implementación (top-down) de la ley 1448 del 2011, con la cual se estructuran los fundamentos de la atención a víctimas, se reconocen los hechos victimizantes, se priorizan las rutas de atención, los enfoques de derechos y diferencial, entre otros, la restitución de tierras y restablecimiento de derechos, así como las bases para la reintegración y la reconciliación social.

Otros de los atributos que toman forma dentro del proceso de construcción de paz, más allá del cese bilateral del fuego y la reducción de homicidios por el conflicto armado, según Rettberg (2012)son: el DDR (desarme, desmovilización y reintegración de excombatientes), la reconciliación, la atención a población vulnerable, la construcción de memoria y verdad, la justicia transicional y la reparación, la prevención de la violencia y el crimen, la reforma de las Fuerzas Armadas y de Policía, la reconstrucción y el desarrollo económico, la estabilización política y la participación del sector privado, la sociedad civil y la comunidad internacional.

Al terminar el conflicto armado y evidenciar el avance de los procesos de construcción de Paz, el tejido social y el campo cultural dejan atrás la realidad de la guerra para iniciar transformaciones, una de ellas como lo sostiene Brounéus, es la Reconciliación social, en la cual, el lenguaje, la comunicación, la educación, las artes y el apoyo a iniciativas locales y endógenas tendrán gran valor para la apropiación generalizada del concepto de vivir en paz: 
After the war, the societal and cultural fabricisd renched with these beliefs. They can be seen in how history is described, how the language isused, in education, the media, theatre etc. In order to live in peace, these beliefsmustbe questioned and transformed. Thechanging of stereotypedbeliefsis a crucial step in the process of reconciliation (...) Similarly, supportin glocal and culturally groundedinitiatives forreconciliation willhave the highest legitimacy and sustainability in the long run. (p. 13-14)

\section{Senda de la reconciliación social}

Por eso, en últimas evoco la memoria de los ancestros y sus deidades anfibias, fiesteras y pacificas. A ellas, y ante todo a ellas, podemos ahora entregarnos, si queremos llegar a la nueva era de progreso y de paz y a la nueva sociedad. La violencia en Colombia (Fals Borda, 2005, p. 22)

María Lucía Méndez (2011) sostiene que a finales de los años 90’s en Suráfrica, el tema de la Reconciliación Social, a nivel global toma auge, por los procesos de post-apartheid que promovieron el reconocimiento de los Derechos Humanos para los grupos poblacionales y pueblos tribales que reclamaban la visibilización de sus necesidades y por lo tanto el reconocimiento político y cultural que por años fue ignorado.

En América del Sur en los años 80's y 90's se empiezan a estructurar procesos de justicia transicional y reconciliación por medio de las Comisiones de la Verdad, como en los casos de Argentina y Chile en el ańo de 1984 y de El Salvador en 1992.

Méndez (2011) sostiene que en Colombia, desde el gobierno del expresidente Virgilio Barco (19861990), el tema de la Reconciliación se ha puesto en la agenda pública. Los gobiernos que le sucedieron, se han caracterizado por introducir en el discurso y en los planes de gobierno, las bondades de la reconciliación pero sin evidenciar avances importantes en el tema del postconflicto.

El concepto de Reconciliación según la CNRR (2006) es mirar la realidad por fuera de la violencia, es fomentar la construcción de las relaciones sociales por medio de una convivencia pacífica y una proyección de país alejado del conflicto.

A partir de la revisión conceptual que efectúa Ugarriza (2012) se reconoce la importancia y prioridad que se le debe asignar al tema de Reconciliación Social como base originaria de procesos a largo plazo; el autor concluye que varias posiciones teóricas sostienen que:

El corazón de la reconciliación en contextos de conflicto armado es, en primera medida, la construcción de confianza y cohesión para abrir paso a una coexistencia pacífica entre ambas partes del conflicto, y una vez superado este reto, sí es posible ahondar en procesos más complejos y de largo plazo. (p. 13)

En particular, para Brounéus (2007) la reconciliación es un proceso social que guarda relación con la historia y que se erige desde la transformación de los individuos hacia la afirmación de intereses colectivos, bajo unos principios que proyecten una paz duradera:

Reconciliation is a societal process that involves mutual acknowledgment of pastsuffering and the changing of destructive attitudes and behavior into constructive relationships to ward sustainable peace. (...) it is a process, not a remote goal to beachieved when war has ended. (p. 6).

Aportando a la construcción teórica y teniendo en cuenta los principios desarrollados por el maestro Orlando Fals Borda, en su concepción de lo que permitiría la construcción de un sistema geosociocultural apropiado para la realidad colombiana y que denominó "socialismo raizal", y aunque aquí no se trata de proponer la construcción de ese sistema social, sí se considera interesante contemplar dichos planteamientos para promover las bases de un escenario territorial y social que se potencialice desde la 
endogénesis, la contextualidad y el trópico, con el único fin de superar las visiones exógenas y potenciar, de acuerdo al contenido de éste capítulo, la reconciliación social como proceso para fortalecer las potencialidades humanas,así como también, fortalecer de las capacidades políticas de las entidades subnacionales "excluidas", de las cuales se hablará más adelante,evitando con ello, no repetir los errores del pasado y caer así nuevamente en el conflicto armado.

\section{La reconciliación social y las potencialidades humanas}

Un aspecto esencial en la Reconciliación Social es la reivindicación de las potencialidades humanas, entendidas como los valores, habilidades sociales o las connotaciones positivas del ser; partiendo del análisis sociológico que efectúa Fals Borda, el autor identifica en Colombia la existencia de los "valores esenciales de la raza cósmica", a saber:

Entre ellos destaco los valores de índole comunitaria y filantrópica, los de ayuda mutua, intercambio de brazos, producción colectiva, resguardos, ayllus, mingas y respeto por la naturaleza, en fin, valores altruistas que no han sido del todo destruidos o desplazados por el moderno individualismo egoísta.(p. 5)

Fals Borda identifica como integrantes de la raza cósmica a las negritudes, a los indígenas, a los campesinos principalmente, en quienes se forjó la idiosincrasia y la mestiza identidad nacional. Se definen como aportes de la raza cósmica por ejemplo, el valor antiseńorial constituido actualmente por quienes defienden la dignidad política y personal desde los gobiernos locales o comunales, por otra parte, también el valor de los colonos o campesinos que huyeron de la guerra para construir una autóctona cultura de paz habitando zonas de frontera agrícola, por último el valor de las comunidades étnicas aportando el significado endógeno de la colectividad, la relevancia del entorno comunitario, la filantropía, el altruismo, el ecologismo, la libertad, la dignidad política y administrativa como la autonomía, la auto-organización, el autogobierno y principalmente, para éste tema en cuestión: la convivencia pacífica.

El valor de estas potencialidades debe posibilitar un encuentro equitativo, como sostiene Orozco (2003), la reconciliación debe afrontar dos procesos, uno horizontal y otro vertical. El vertical representa un vínculo entre víctima y victimario donde se enfatiza en la iniciativa del perdón. En el horizontal se enfatiza en la búsqueda de confluencia de realidades y de comprensión de las mismas, con el fin de trazar parámetros de proyección hacia futuro. Para ello se debe afianzar en la construcción de imaginarios desde la familia, el barrio y la escuela como escenarios de enseñanza para la promoción de la paz.

La reconciliación debe afianzar la creencia en las capacidades de las personas. Según Max-Neef (1986), las capacidades o habilidades de las personas se fomentan cuando se destinan a la defensa de sus necesidades (axiológicas y existenciales) y a la realización de sus libertades; para el autor es imprescindible que las personas vivan sus necesidades: de ser, tener, hacer y estar, y axiológicas: de subsistencia, protección, afecto, entendimiento, participación, ocio, creación, identidad y libertad.Por lo tanto las necesidades no representan carencias sino potencialidades humanas individuales y colectivas; éstas se viven por medio de satisfactores, entre los cuales se entiende la reconciliación social, que en sí cubre varias necesidades.

Por otra parte y en particular la reconciliación en Colombia, en donde a pesar de las diversas reformas persisten problemáticas asociadas a la corrupción, débil cultura política, ineficiencia institucional, etc., debe desenvolverse bajo un escenario deliberativo que según Ugarriza (2012), presupone "participación libre, igual y plural (2), en condiciones de respeto (3) y dedisposición a ceder ante el mejor argumento (4), y dirigida a la buisqueda del bien común y losideales de la justicia distributiva liberal (5)”.(p. 14)

Por su parte Habermas (1991) complementa el concepto de política deliberativa así: 
la deliberación, en lo que a su contenido se refiere, puede apoyarse en un consenso de fondo entre los ciudadanos (...) La teoría del discurso toma elementos de ambas partes y los integra en el concepto de un procedimiento ideal para la deliberación y la toma de resoluciones. Este procedimiento democrático establece una interna conexión entre negociaciones, discursos de auto entendimiento y discursos relativos a cuestiones de justicia, es decir, entre tres formas distintas de comunicación, cada una de las cuales tiene su propia lógica.(p. 5)

En complemento, la Reconciliación puede contemplar la idea de una justicia restaurativa. Así, como lo plantea Beristain (2005) la justicia restaurativa es un mecanismo que le da paso al factor de reparación y de cumplimiento de la justicia en el marco de los derechos humanos pero sin tanto peso como la justicia retributiva, es decir, no enfatiza en el castigo, sino más bien, en el diálogo y en la proyección del arrepentimiento y la responsabilidad, entre los directamente involucrados en el conflicto, permitiendo la formulación de compromisos.

Charles Villa-Vicencio (2006) concluye que se trata de la creación de una relación ética para abordar los conflictos destinando a la justicia retributiva gran relevancia como:

Itconcernsthe establishment of anethical relationship as a basison which formerenemies and antagonists can address prevailing problems in a viable and cooperative manner. Political reconciliation regards justice as anessential ingredient to reconciliation, recognizing that there are diferente ways of achieving and of defining justice. In societie semerging from violent conflict, thiskind of reconciliation is often the only realistic alternative to enduring the escalating violence - and of achieving economic, social, and related forms of justice.

\section{Senda de diseńo institucional}

Esta senda prioriza la necesidad de una estabilidad política que se estructure a partir del proceso de transición hacia el postconflicto y de acuerdo a ello a partir de un diseño institucional que abarca la construcción de "la redacción constitucional, la ingeniería de sistemas electorales, la implementación de mecanismos de representación y participación, la cesión de autonomías y la composición de los poderes del Estado" (Ugarriza, 2013, p 147), según el autor, se debe incluir también, las nuevas propuestas en torno a la promoción de la democracia deliberativa en los escenarios de postconflicto y que requieren, en primera instancia, de la legitimación e implementación de mecanismos que brinden las condiciones para ello. Una de esas condiciones para el afianzamiento de cesión de autonomías, la armonización de los poderes del Estado e incluso el fortalecimiento de los mecanismos de representación, considero,es la descentralización, pero orientada al aumento de capacidades políticas en las denominadas "entidades subnacionales excluidas" que se detallan más adelante.

\section{La descentralización como aumento de capacidades políticas para afrontar el postconflicto desde y en las "entidades subnacionales excluidas"}

Entender la descentralización como aumento de capacidades permitiría focalizar positivamente las nuevas potencialidades, como por ejemplo, de excombatientes que se integran a la vida civil ydiseñaran su proyecto personal y familiar en un territorio determinado (departamento, municipio o vereda). La Reconciliación Social, por lo tanto, requiere que las entidades subnacionales así como el sistema de partidos, figuren en dicho proceso como "buenos componedores" o garantes de su reinserción, con nuevas oportunidades para no caer en la pobreza y exclusión generadas, entre otras causas, por la desintegración regional, y que podrían arrojar al individuo, posiblemente, a vincularse nuevamente a grupos armados, como única opción de sustento e incluso de "arraigo". Pero ¿Por qué hablar de aumento de capacidades? Y bajo ¿qué perspectiva? 
De acuerdo a lo anterior, Brounéus (2003), considera que para lograr una Paz sostenible en una sociedad en conflicto, es vital integrar las raíces de una nación como sus tradiciones y cultura, sin importar si ya se han cimentado o internalizado algunas características exógenas: "These arch for sustainable peace in a society after conflicto must begin from its own roots, importing from outside whatever can be of use, but basing that society's transformation onitsown unique set of traditions and cultural heritage". (p.22).

En relación, Fals Borda sintetiza precisamente que las capacidades son:

Capacidades históricas heredadas del aporte antiseñorial que trajeran los campesinos espańoles en la colonia y se implementaran en territorio colombiano 'tales como los cabildos abiertos y mayores, y los fueros citadinos y antiseñoriales que los nobles y los reyes debían jurar respetar. Constituyen una pequeña semilla libertaria de no pequeña importancia, cuyos sucesores en nuestras viejas comarcas y provincias son los actuales concejos municipales, corregidores y otras prácticas de gobierno local independiente, esto es, casi sin ninguna presencia de un Estado central. (2003, p. 6).

\section{Contexto: la descentralización y el sistema político}

Los países latinoamericanos, en los últimos 25 años experimentaron cambios sustanciales en su contexto político. Para Montero y Samuels (2004) la descentralización ha sido clave en las diversas transformaciones políticas que los Estados andinos han llevado a cabo en los últimos decenios. Agregan, sin embargo, que el principal foco de interés en la historia de América Latina, ha estado puesto en la tradición centralista de la política latinoamericana cuya trayectoria comienza con las instituciones coloniales.

Los autores definen tres partes de la descentralización: laPolítica que es la capacidad y posibilidad de que los niveles de gobierno sean conformados o elegidos por voto popular directo, lo que propiciaría una apertura de nuevos espacios para la competencia nacional y sub-nacional, entendido esto en que, los espacios de poder se multiplican. La Económica-fiscal, asignándole recursos propios a los entes sub-nacionales para el cubrimiento de sus propios gastos y la Administrativa, por lo que se optimizarían los servicios.

Sin embargo, en cuanto al sistema político en Colombia, se asume que la descentralización afecta negativamente la estructura de los sistemas de partidos ya que ha fragmentado el marco institucional de la competencia política. Es decir, en la medida en que la descentralización hace más dispersos los recursos, intereses y responsabilidades de las entidades sub-nacionales, crea incentivos para el surgimiento de partidos políticos de carácter sub-nacional. Esto, desde luego, va en detrimento de un sistema de partidos bien estructurado.

Mardones (2006), define la descentralización como "una transferencia de poder político, dineros fiscales y/o atribuciones administrativas a gobiernos sub-nacionales, se trata en esencia de una redistribución de recursos de unos actores hacia otros. El problema, nuevamente, se identifica en el arraigo histórico hacia el centralismo y por otra parte, en la débil capacidad de los gobiernos locales para abarcar el territorio, tanto por el desconocimiento de las necesidades territoriales como por la desintegración territorial.

En este sentido, O’Neill (2008) señala que la descentralización es parte de la estrategia electoral de los partidos en cuanto estos ven a la descentralización como una oportunidad de maximizar sus resultados electorales. Según el autor, existe una crisis de la representación democrática, en el marco de los "supuestos efectos de la descentralización", que se configura en torno a: la concurrencia de los votantes, la volatilidad electoral de los partidos y el aumento del número de candidatos independientes a la presidencia; en cuanto a este tema, $\mathrm{O}^{\prime}$ Neil afirma que en Perú, por ejemplo, se motiva a candidatos a presentarse en plataformas independientes; Bolivia lo impide mientras que en Colombia se motiva a candidatos independientes a presentarse con el apoyo de grandes partidos políticos. 
Sin embargo, en relación con el contexto actual colombiano y el postconflicto, se busca de alguna forma desmontar algunos desenlaces que produjo la descentralización al sistema político, pero teniendo en cuenta las dificultades territoriales para superar la crisis de gobernabilidad (corrupción, clientelismo), el conflicto armado y la desintegración de las regiones para dar respuesta a sus necesidades; por ello se plantea la siguiente pregunta: ¡la actual descentralización en Colombia, como diseńo institucional, aporta positivamente al aumento de las capacidades del sistema de político; el sistema político, como diseño institucional, se contempla como una estructura sólida que enfrente las necesidades de las entidades sub-nacionales y el postconflicto?

\section{La descentralización y las privaciones políticas subnacionales}

Según O’Neil (2008) la descentralización es una reforma o serie de reformas que incrementan el poder político por medio de la elección de funcionarios sub-nacionales que antes eran designados, pero también, la descentralización otorga cierto nivel de capacidad autónoma a esos niveles sub-nacionales que, de no estar preparados para fortalecer dicha autonomía, ésta estará alejada de las realidades en los territorios.

Existen para el autor tres elementos dentro de un régimen político: la legitimidad o el sistema de creencias de que para un país, ningún otro régimen podría asegurar un mayor éxito de los objetivos colectivos; la Eficacia o la capacidad del régimen para encontrar soluciones a problemas básicos con los que se enfrenta todo sistema político que son percibidos más como satisfactorios que insatisfactorios por los ciudadanos; y la efectividad o la capacidad para poner en práctica las medidas formuladas con el resultado deseado. Pero ¿qué tan legítimo, eficaz o efectivo es el sistema político en Colombia frente a las privaciones territoriales que surgen a consecuencia del conflicto armado, la corrupción y clientelismo, incluso, la desintegración regional frente a la formulación de políticas públicas que atiendan las particularidades del postconflicto?

Es importante formular el análisis desde el planteamiento de Sen (2000) en cuanto a las privaciones, que nos puede ilustrar algunas respuestas. Para Sen, las privaciones como la falta de salud, la falta de convivencia pacífica, la falta de educación, de participación, la exclusión social y la desnutrición, que son representaciones de pobreza y desigualdad, se deben priorizar e incluir dentro de las políticas económicas y sociales con mayor fuerza que solo la renta.

Por lo tanto, no solo la renta debe dominar el debate político acerca del aumento de autonomía o capacidades en los territorios, la región posee privaciones como la pobreza que obstaculizan la posibilidad de generar procesos de desarrollo y transformación cualitativa de sus habitantes, y en este aspecto los partidos políticos, no han aprovechado los procesos de descentralización, para integrar espacios o entidades sub-nacionales con características socioeconómicas e histórico-culturales semejantes para superar algunas de esas privaciones.

Así, las privaciones en una sociedad o región se entienden como una privación en el sistema político, en sus partidos mismos. Sen, analiza que es necesario comparar las situaciones de pobreza y desigualdad teniendo en cuenta las particularidades de cada región y país para definir las privaciones más representativas que deben superarse; y el sistema político y sus partidos deben contemplar como esencial en su agenda este ejercicio práctico con el fin de proveer eficacia, eficiencia y efectividad en sus acciones políticas, más aún en los espacios sub-nacionales donde la descentralización les aporta herramientas que optimizarán sus capacidades, capacidades por ejemplo, en la toma de decisiones frente a políticas públicas en torno al postconflicto. 
Así, el sistema político de la mano con la descentralización, puede aumentar sus capacidades. Para Francisco Gutiérrez (2010), esto se conoce como una nueva forma de nacionalización promovida por:

- Modalidades de autogobierno que construyan estado-nación.

- Promoción de políticas públicas autónomas municipales.

- Crear una unidad intermedia entre municipio y nación.

- Un Sistema de incentivos para unidades sub-nacionales.

- Crear diseños diferenciados a partir de las capacidades y características de las regiones.

- Rediseño de los Fondos de Regalías que promuevan más desarrollo y menos ilegalidad.

- Fortalecer el Departamento Nacional de Planeación como una unidad de desarrollo territorial.

\section{Las entidades sub-nacionales excluidas: aumento de capacidades políticas}

La autonomía se erige como principal determinante de la descentralización, en Colombia es un derecho amparado en la constitución, así mismo en ésta, se conciben las unidades territoriales que pueden acceder a dicha autonomía, no solo fiscal sino también política. Las unidades territoriales en vigencia son el municipio, el distrito y el departamento, pero hay otras tres entidades que figuran como el principal reto de la descentralización, y que defino como "entidades sub-nacionales excluidas" las cuales son: las Entidades Territoriales Indígenas (ETIS), la Provincia y la Región.

Según el sociólogo Orlando Fals Borda (2013), "la descentralización, para que tenga éxito, necesita de un ordenamiento simultáneo" (...) "Ordenamiento y descentralización deben ser tratados como hermanos siameses". Para Borda, es de vital importancia fortalecer las entidades territoriales constitucionales olvidadas en el papel, son estas las ETIS, las provincias y las regiones; la descentralización fiscal, administrativa y política debe basarse en estas tres entidades, afianzarlas, y con mayor posibilidad, el sistema político se fortalecerá en el torno a estas entidades.

Fals Borda propone frente a esta problemática, crear una república regional unitaria, una unión de regiones, basadas en las ETIS, la provincia y la región, extinguir la figura del departamento el cual, hasta el momento, es el principal escenario de acción para ejercer la descentralización como la participación política de los partidos y los movimientos. Fortaleciendo las regiones históricogeográficas, la participación de los partidos y el accionar de las instituciones promoverán a formar sujetos capaces de reconocer sus potencialidades y valores para proyectarlos en procesos realmente transformadores.

Es decir, la descentralización requiere de un ordenamiento espacial y por ende político acorde con las características culturales que permita un nivel coherente de desarrollo local, la superación de un proceso de toma de decisiones legislativas reactivas y el fortalecimiento de capacidades políticas en las entidades sub-nacionales que promuevan políticas públicas que superen las privaciones generadas a consecuencia del conflicto armado y la desarticulación territorial.

\section{Partidos y entidades sub-nacionales}

Las debilidades del sistema político para representar algunos sectores sociales, y su incapacidad para atender a sus demandas, son a su vez causas próximas/institucionales y sistémicas/estructurales. Además de la evidente conexión entre la disponibilidad de recursos ilegales y persistencia de grupos armados en el país, se identifica también sugerida, una conexión entre debilidad de la democracia y violencia: la histórica desconexióndel sistema político por parte de importantes sectores de la población colombiana -o surelacionamiento por vías ilegales y redes clientelistas y de cooptación-, y la incapacidadinstitucional para promover bienestar y seguridad material contribuyen a la continuación del conflicto. (Gonzales, 2003). 
El afianzamiento de las "entidades sub-nacionales excluidas", permite comprender en la dinámica política, la incidencia de los partidos, sus prácticas y su sistema de creencias. El sistema de partidos en Colombia ha generado cambios significativos según los Actos Legislativos 001 de 2003 y 001 de 2009 y la Ley 1475 de 2011 superando la tradición bipartidista y el centralismo característico de principios de siglo XIX en Colombia, sin embargo, cambios que con el tiempo provocó la disminución del campo de acción de los partidos y la intervención de organizaciones ilegales. En vista de lo anterior, se evidencia que la profesionalización de los partidos y la estructuración como nuevo diseño institucional, debe basarse en la valoración de las "entidades sub-nacionales excluidas": las ETIS, las provincias y las regiones.

\section{Conclusión}

\section{¿Es posible la construcción de una paz raizal?}

La construcción de paz, la reconciliación social y el nuevo diseño institucional para el postconflicto deben basarse en principios de endogénesis, contextual y de trópico, éstas deben afianzarse desde la promoción de prácticas de democracia deliberativa y de justicia restaurativacomo herramientas de transformación cultural.

Para un periodo de postconflictoes necesario fundamentar los cimientos desde la interpretación de un ethos no violento que fluye de aquellos grupos originarios fincados en el medio tropical, un ethos no violento que comparte la sabiduría contextual y experiencial y la defensa autonómica de sus sociedades y territorialidades. Las sendas para el postconflicto deben estructurarse bajo estos elementos estratégicos.

\section{Referencias}

Arteaga Botello, N. (2006). Reseña de "Tanscender y transformar. Una introducción al trabajo de conflictos de Johan Galtung”. En: Espacios Públicos, volumen 9, No. 17, p. 481-484. Recuperado de http://www.redalyc.org/articulo.oa?id=67601733.

Behar, Olga. (1985). Las guerras de la Paz. Planeta Colombiana Editorial. Bogotá.

Beristain, Carlos M. (2005). Reconciliación luego de conflictos violentos: un marco teórico. En: IDEA, Verdad, justicia y reparación. Desafíos para la democracia y la convivencia social.

Brounéus, Karen. (2003). Reconciliation: Theory and Practice for Development Cooperation. Stockholm: The Swedish International Development Cooperation Agency.

Comision Nacional De Reparación Y Reconciliación. (Enero 17 de 2006). "Definiciones estratégicas". Recuperada en: hptt/:www.cnrr.visióndirecta.com/09e/spip.php?article7

Cuervo, J.I.; Hernández, A. y Ugarriza, J.E. (eds.) (2012). El giro deliberativo en la democracia. Teoría y evidencia empirica. Bogotá: Universidad Externado de Colombia.

Charbonneau, B y Parent, G. (edit) (2012). Peacebuilding, memory and reconciliation: Bridging top-down and bottom-up approaches. Graduate Institute of Intenational and Development Studies. Routledge. Geneve.

Esther Del Campo (2007). Participación política y democracia local en Bolivia. En: Esther Del Campo, Democratización y descentralización en Bolivia, Madrid: Los libros de la Catarata, pp. 15-42.

Fals Borda, Orlando. (1998). Guía práctica de ordenamiento territorial en Colombia: contribución para la solución de conflictos. Instituto de Estudios Políticos y Relaciones Internacionales (IEPRI). Universidad Nacional de Colombia, Bogotá.

Nacional. Bogotá.

(2005). La violencia en Colombia. Tomo I. Prólogo. Editora Aguilar. Bogotá.

.(2013). Socialismo raizal y el ordenamiento territorial. Bogotá: Ediciones Desde Abajo. 
Gutiérrez S. Francisco (2010). “Instituciones y territorio. La descentralización en Colombia”, en 25 años de la descentralización en Colombia, Konrad Adenauer Stiftung (Colombia), pp. 15-59.

Habermas, J. (1991). Tres modelos de democracia. Sobre el concepto de una politica deliberativa. Universidad de Francfort. (Traducción castellana de Manuel Giménez Redondo). Conferencia pronunciada en el Departamento de Filosofía de la Universitat de Valencia. En: Instrumentos de Trabajo, vol. 43 València, 1994. Ediciones Episteme, S.L. Col. Eutopías.

Justicia y Nación. (2015, 4 de enero), Medellín, clave en histórica caída de homicidios en Colombia [versión electrónica]. El tiempo.com. Recuperado el 27 de julio de 2015, de http:/www.eltiempo.com/politica/justicia/cayo-cifra-dehomicidios-en-colombia/15050055.

Karen Brounéus (2007). Reconciliation and Development. Dialogue on Globalization N 36, Friedrich-Ebert-Stiftung. Belin.

Mardones, R. (2006). Descentralización y transición en Chile. En: Revista de Ciencia Política, Vol. 26 (Nº 1), 03-24.

Max-Neff, M; Elizalde, A; Hoppenhayn, M. (1986) Desarrollo a Escala Humana: una opción para el futuro. Santiago, Chile: Fundación DagHammarskjold. CEPAUR.

Méndez, María L. (2011). Revisión de la literatura especializada en Reconciliación. FESCOL-CERCAPAZ. Bogotá.

Montero, A., \& Samuels, D. (2004). The Political Determinants of Decentralization in Latin America: Causes and Consequences. En A. S. Montero, Decentralization and Democracy in Latin America. University of Notre Dame.

Ordoñez-Matamoros, G. (2013). Manual de análisis y diseño de políticas públicas. Universidad Externado de Colombia. Bogotá.

Orozco, Iván (2003). La posguerra colombiana: divagaciones sobre la venganza, la justicia y la reconciliación. Análisis político No. 46. Colombia.

O’Neil, Kathleen (2008). Política descentralizada y resultados políticos en los países andinos. En: Scott Mainwaring, Ana María Bejarano y Eduardo Pizarro (eds.), La crisis de la representación democrática en los países andinos, Bogotá: Grupo Editorial Norma, pp. 263-310.

Política. (2014, 9 de diciembre), El conflicto cauó 310.000 víctimas en año y medio [versión electrónica]. El tiempo. com. Recuperado el 27 de julio de 2015, de http://www.eltiempo.com/politica/justicia/victimas-durante-el-conflictoarmado/14947955

Puyana, José (2012). Las reformas políticas en Colombia, 2003-2011: ¿hacia partidos más responsables?. En: Laura Wills Otero y Margarita Batlle (comp.), Política y territorio. Análisis de las elecciones subnacionales en Colombia 2011, Bogotá: PNUD-IDEA Internacional-NIMD, p.17-62.

Rettberg, Angelika (coord.) (2002). Preparar el futuro: conflicto y posconflicto en Colombia. Universidad de los Andes. Fundación Ideas para la Paz. Bogotá.

. (2003). Diseñar el futuro: una revisión de los dilemas de la construcción de paz para el post conflicto. Revista de Estudios Sociales No, 15, p. 15-28.

. (2012). Construcción de paz en Colombia: contexto y balance. En:Construcción de paz en Colombia, (comp). Bogotá: Ediciones Uniandes.

Sen, Amartya (2000). Desarrollo y libertad. Buenos Aires: Editorial Planeta.

Ugarriza, Juan; Martínes, Usdin y Gutiérrez, Natalia. (2012). Mesas de deliberación política para el postconflicto: una estrategia de reconciliación y profundización de la democracia. En: La participación ciudadana desde diferentes perspectivas. Revista Centro de Estudios Políticos, No. 7, Año 2012. Ministerio del Interior. Bogotá D.C.

Ugarriza, J. (2013). La dimensión política del postconflicto. Discusiones conceptuales y avances empíricos. En: Colombia Internacional No. 77 (p. 141-176). Universidad de los Andes. Bogotá.

Villa-Vicencio, Charles. (2006). ThePolitics of Reconciliation. In: Tristan Anne Borer, (ed) Tellingthetruths: Truth and peacebuilding in post-conflict societies. University of Notre Dame Press. Notre Dame. P. 59-81. 